\title{
Advances in Fluorescence Sensing Systems for the Remote Assessment of Nitrogen Supply in Field Corn
}

\author{
Corp. L.A., E.W. Chappelle, J.E. McMurtrey, C.S.T. Daughtry, M.S. Kim \\ USDA ARS Remote Sensing and Modeling Lab.,BARC-West BIdg. 50 Rm 14 \\ 10300 Baltimore Ave, Beltsville MD 20705 \\ (301) 504-5604 Icorp@asrr.arsusda.gov
}

\begin{abstract}
The studies described herein were conducted to better define changes in fluorescence properties of leaves from field grown corn (Zea mays L.) as they relate to varying levels of nitrogen (N) fertilization. This research was directed toward: 1) providing a remote non-destructive sensing technique to aid in the determination of optimal rates of $\mathrm{N}$ fertilization in corn crops and, 2) defining parameters for furthe development of fluorescence instrumentation to be operated remotely at field canopy levels. Fluorescence imaging bands centered in the blue $(450 \mathrm{~nm})$, green $(525 \mathrm{~nm})$, red $(680 \mathrm{~nm})$, and far-red $(740$ $\mathrm{nm})$ and ratios of these bands were compared with the following plant parameters: rates of photosynthesis, $\mathrm{N}: \mathrm{C}$ ratio, pigment concentrations, and grain yields. Both the fluorescence and physiological measures exhibited similar curvilinear responses to $\mathrm{N}$ fertilization level while significant linear correlations were obtained among fluorescence bands and band ratios to certain physiological measures of plant productivity. The red / blue, red / green, far-red / blue, far-red /green fluorescence ratios are well suited for remote observation and provided high correlations to grain yield, LAI, $\mathrm{N}: \mathrm{C}$, and chlorophyll contents. The results from this investigation indicate that fluorescence technology could aid in the determination of $\mathrm{N}$ fertilization requirements for corn. This discussion will also address design concepts and preliminary field trials of a mobile field-based Laser Induced Fluorescence Imaging System (LIFIS) capable of simultaneously acquiring images of four fluorescence emission bands from areas of plant canopies equaling $1 \mathrm{~m}^{2}$ and greater without interference of ambiẹnt solar radiation.
\end{abstract}

\section{INTRODUCTION}

Green vegetation, when excited by specific wavelengths of light, dissipate a portion of the absorbed energy as light emissions in the form of fluorescence. Leaf level fluorescence emissions occur in five primary regions of the spectrum, namely; ultraviolet (UV), blue, green, red, and far-red [1,2]. Several investigators have demonstrated relationships between these fluorescence intensities and ratios of these intensities to various forms of plant stress. Fluorescence measurements have shown a great deal of promise in the remote detection of plant stress conditions. Currently, several research groups are utilizing Laser Induced Fluorescence (LIF) systems from a variety of platforms to receive fluorescence information and are relating this information to the physiological status of the plants in both terrestrial and aquatic ecosystems [5,6].

Fluorescence emissions from green vegetation typically involve a convolution of spectral emissions from several plant constituents. The present studies were designed to investigate relationships between in vivo fluorescence spectra, pigment concentrations, and elemental composition; primarily N. The results from these studies will serve as the basis for the development of algorithms for the remote assessment of plant stress conditions in corn induced by varying $\mathrm{N}$ supply. The present studies will aid in the development of fluorescence instrumentation to sense degrees of plant growth and condition. This information could be incorporated for the site specific variable applications of $\mathrm{N}$ containing fertilizers for crop production.

\section{INSTRUMENTATION AND MATERIALS}

\section{Plant Material}

Corn (Zea mays L. 'Southern States 812') was grown on a Codorus sandy loam soil at the USDA Beltsville Agricultural Research Center. The experimental design was a randomized complete block with four blocks containing eight $\mathrm{N}$ treatments leading to a total of 32 treatment plots. The treatments were selected as $150,125,100,75,50,25,12,0 \%$ of the recommended rate of $162 \mathrm{~kg} \mathrm{~N} /$ ha as determined by the University of Maryland Soil Testing Laboratory. The N fertilization rates were selected to provide plant growth conditions ranging from classical symptoms of $\mathrm{N}$ deficiency to physiological conditions consistent with an excess supply of $\mathrm{N}$. Fluorescence and physiological measurements from field corn were obtained from the uppermost fully expanded leaves at the vegetative (VI2), tasseling (VT), and grain fill (R3) growth stages. The laboratory based fluorescence imaging system (FIS) was used to obtain the leaf level fluorescence emissions and these emissions were correlated with grain yield, LAI, $\mathrm{N}: \mathrm{C}$, and chlorophyll contents.

\section{Leaf Level Fluorescence Imaging System}

The fluorescence imaging system (FIS) consisted of a UV excitation source, a digital image detection camera, and a computer interface for data collection and instrument control. The UV excitation source consisted of four UV-A fluorescent lamps (Model EA-180/12, Spectroline Inc., USA). These 
lamps were arranged in an $45^{\circ}$ angle toward a central target area approximately $0.2 \mathrm{~m}$ above the sample surface to provide nearly uniform illumination centered at $365 \mathrm{~nm}$ with an intensity of $0.33 \mathrm{~mW} / \mathrm{cm}^{2}$. The radiation from the UV lamps was filtered with Schott UG-1 glass to eliminate radiation greater than $400 \mathrm{~nm}$ that could interfere with fluorescence emission. The detection system consisted of a cooled CCD camera (Lynxx-2, SpectraSource Instruments, Westlake Village, CA. USA) coupled to an $\mathrm{f} / 3.5,20 \mathrm{~mm}$ lens which captured a $12 \mathrm{~cm}^{2}$ area in to a 12 bit, $196 \times 165$ pixel file. The camera was attached to an automated filter wheel $(A B 300, C V I$ Laser Corp., USA) which contained two band pass interference filters centered at $450 \mathrm{~nm}, 550 \mathrm{~nm}, 680 \mathrm{~nm}$, and $740 \mathrm{~nm}$. The camera responsivity and variation due to non-uniform illumination for the system were calibrated using a flat field fluorescent target.

\section{Canopy Level Laser Induced Fluorescence Imaging}

The advent of the laser provided an ideal excitation source for fluorescence. Lasers are capable of emitting coherent light with a very high degree of monochromaticity and intensity which is necessary to obtain measurable fluorescence from vegetation. The excitation components for LIFIS (Laser Induced Fluorescence Imaging System) consists of a SpectraPhysiscs frequency-tripled Nd:YAG laser. The laser operating at $10 \mathrm{~Hz}$ emits $125 \mathrm{~mJ}$ of $355 \mathrm{~nm}$ radiation per pulse. Placement of an expanding divergent lense system at the laser beam exit enables manipulation of the laser beam to provide an adjustable area of illumination.

The detection components of LIFIS consist of a 12-bit 2 stage peltier forced air cooled $C \mathrm{CD}$ camera which provides a super VGA resolution of $1280(\mathrm{H}) \times 1024(\mathrm{~W})$ pixels. The camera is coupled through an ultra speed . $22.5 / 105 \mathrm{~mm}$ distortion free tandem lens to a fast gated $25 \mathrm{~mm}$ P20 phosphor screen image intensifier. The gate unit has an intrinsic $50 \mathrm{~ns}$ delay and the fluorescence emissions are collected within a 100 ns exposure window following each laser pulse. Operation within this time domain eliminates any measurable interference from ambient solar radiation.

Attached to the camera is a multispectral lense which is a common aperture imaging spectrometer system that separates four spectral images spatially on the two dimensional detector array. The four spectral images are acquired simultaneously with no moving parts through four $10 \mathrm{~nm}$ FWHM (full width at half maximum) band pass interference filters centered in; the blue at $450 \mathrm{~nm}$, the green at $530 \mathrm{~nm}$, the red at $680 \mathrm{~nm}$, and the far-red at $730 \mathrm{~nm}$. Following the multispectral lense is a Cannon F1:1.6/11-110 mm electronic TV zoom lense. The simultaneous four band acquisition enables one to obtain accurate ratios of image bands on mobile platforms while avoiding the effects of leaf and instrument movement and random pulse to pulse variations in laser power.

LIFIS is entirely computer controlled via a 132 Mbyte burst rate $\mathrm{PCl}$ interface board connected to the camera through a 10 $\mathrm{m}$ fiber optic link. The system is capable of acquiring 10 four spectral band fluorescence images per second in the presence of ambient solar radiation. Currently, LIFIS is mounted for operation within a mobile van laboratory equipped with an AC generator and remote control deployment boom provided by Biospheric Sciences Branch, NASA/GSFC, Greenbelt, Maryland.

\section{RESULTS AND DISCUSSION}

A large number of significant correlations were noted among leaf level fluorescence image band ratios and physiological measures of plant productivity (table 1). Overall, consistently high correlations across growth stages were noted among the red / blue, red / green, far-red / blue, far-red /green bands to total chlorophyll concentration, leafN:C, LAI, and grain yield. The highest correlations were noted at the grain fill growth stage for the red / green ratio of imaging bands and grain yield $(r=0.92)$, LAI $(r=0.82)$, total chlorophyll concentration ( $r$ $=0.96)$, and the $N$ to $C$ ratio $(r=0.94)$. Similarly high correlation were also noted at the vegetative growth stage for the red/far-red, red/green, and far-red/green ratios. Overall the correlation coefficients were higher and more consistent across growth stages with fluorescence band ratios as compared to the single band image means (data not shown).

Table 1. Comparison of linear correlation coefficients ( $r$ ) of fluorescence imaging band ratios to the following physiological measures of plant productivity; total chlorophyll concentration, the ratio of leaf $\mathrm{N}$ to $\mathrm{C}, \mathrm{LAI}$, and grain yield. Measurement dates $V, T$, and $G$ correspond to vegetative $(\mathrm{n}=32)$, tasseling $(n=32)$, and grain fill $(n=16)$ respectively.

\begin{tabular}{|cccccc|}
\hline $\begin{array}{c}\text { Band } \\
\text { Ratio }\end{array}$ & $\begin{array}{c}\text { Growth } \\
\text { Stage }\end{array}$ & $\begin{array}{c}\text { Total } \\
\text { Chl }\end{array}$ & N:C & LAI & Yield \\
\hline Red $/$ & $\mathrm{V}$ & $0.79^{* *}$ & $0.85^{* *}$ & $0.73^{* *}$ & $0.75^{*}$ \\
Far- & $\mathrm{T}$ & $0.49^{* *}$ & $\mathrm{~ns}$ & $0.63^{* *}$ & $0.44^{*}$ \\
Red & $\mathrm{G}$ & $0.53^{*}$ & $\mathrm{~ns}$ & $0.71^{*}$ & $0.69^{*}$ \\
\hline Red / & $\mathrm{V}$ & $0.75^{* *}$ & $0.82^{* *}$ & $0.71^{* *}$ & $0.71^{*}$ \\
Blue & $\mathrm{T}$ & $0.73^{* *}$ & $0.65^{* *}$ & $0.74^{* *}$ & $0.62^{*}$ \\
& $\mathrm{G}$ & $0.94^{* *}$ & $0.91^{* *}$ & $0.80^{*}$ & $0.87^{*}$ \\
\hline Red / & $\mathrm{V}$ & $0.89^{* *}$ & $0.88^{* *}$ & $0.86^{* *}$ & $0.72^{*}$ \\
Green & $\mathrm{T}$ & $0.77^{* *}$ & $0.83^{* *}$ & $0.87^{* *}$ & $0.75^{*}$ \\
& $\mathrm{G}$ & $0.96^{* *}$ & $0.94^{* *}$ & $0.82^{*}$ & $0.92^{*}$ \\
\hline Far- & $\mathrm{V}$ & $0.69^{* *}$ & $0.75^{* *}$ & $0.66^{* *}$ & $0.64^{*}$ \\
Red / & $\mathrm{T}$ & $0.75^{* *}$ & $0.67^{* *}$ & $0.71^{* *}$ & $0.63^{*}$ \\
Blue & $\mathrm{G}$ & $0.66^{*}$ & $0.64^{*}$ & $\mathrm{nS}$ & $\mathrm{ns}$ \\
\hline Far- & $\mathrm{V}$ & $0.89^{* *}$ & $0.87^{* *}$ & $0.86^{* *}$ & $0.70^{*}$ \\
Red / & $\mathrm{T}$ & $0.81^{* *}$ & $0.87^{* *}$ & $0.88^{* *}$ & $0.79^{*}$ \\
Green & $\mathrm{G}$ & $0.73^{* *}$ & $0.70^{*}$ & $0.78^{*}$ & $0.81^{*}$ \\
\hline
\end{tabular}

* t-test probability coefficient $(0.0 \mathrm{I} \leq \mathrm{p} \leq 0.05)$.

** $t$-test probability coefficient $(p<0.01)$. 


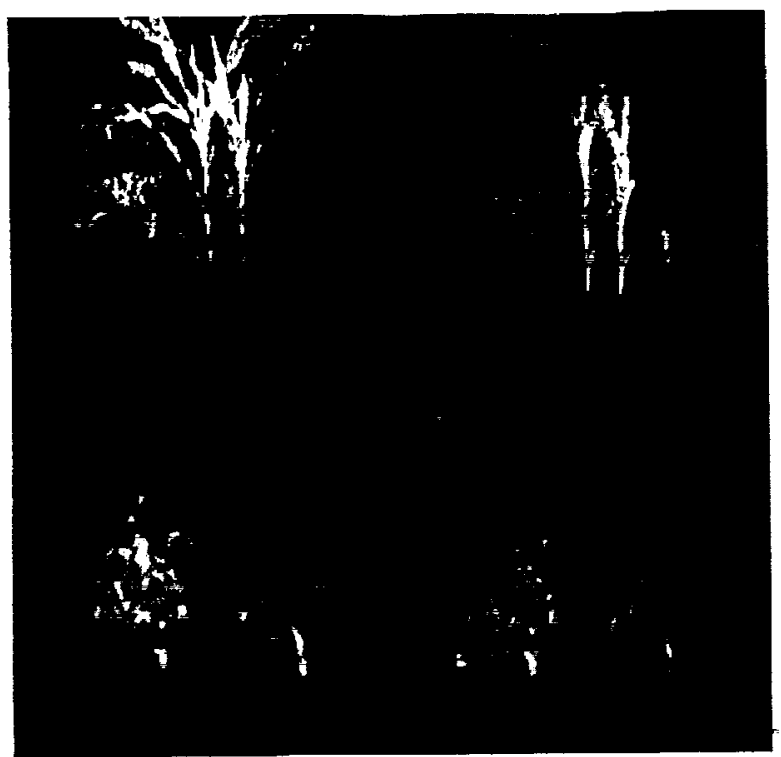

Figure 1 Simultaneous acquisition of four fluorescence emission bands from a corn and soybean plant with LIFIS.

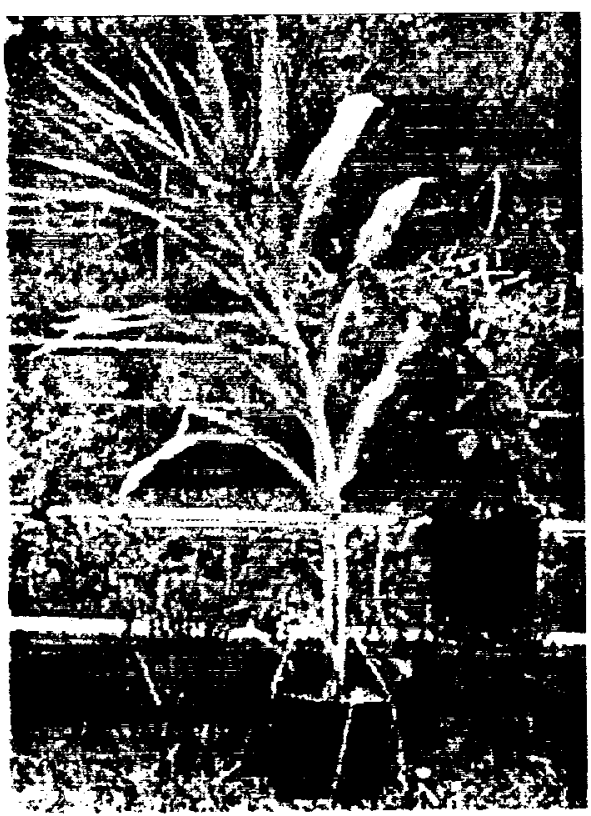

Figure 2 Color photograph corresponding to the LIFIS image shown in figure 1

\section{CONCLLSIONS}

The data presented in the current study indicated that there are several regions from the fluorescence emission spectrum which can be utilized to differentiate corn vegetation grown at varying rates of $\mathrm{V}$ fertilization. FIS has enabled fluorescence spatial characterizations to be made over leat surfaces as well as other components of the plant. This information has pointed to the utility of a imaging system where canopy level fluorescence emissions can be broken down for analysis of the plant components whose fluorescence emissions best indicate the stress condition of interest.

With the increased availability of high intensity fixed emission solid-state lasers, and rapid advances in fast gated CCD (charged coupled diode) detection technologies, the development of such a system has become possible. LIFIS is capable of differentiating fluorescence emissions from ambient solar radiation as indicated with the LIFIS images presented here. Problems associated with movement of the target (i.e., leaf movement under windy conditions) and use of LIFIS on a moving platform such as an aircraft are removed by the simultaneous acquisition of four fluorescence emission bands within each pulse of the laser. The use of fluorescence band ratios will help eliminate problems associated with heterogeneity in laser illumination and pulse to pulse variations in laser power. The fluorescence ratios presented in this study will be further investigated for the differentiation of plant stress condition at the canopy levels.

\section{REFERENCES}

[1] Chappelle, E., F. Wood, J. McMurtrey, and W. Newcomb, "Laser induced fluorescence (LIF) of green plants. II: A technique for the remote detection of plant stress and species differentiation," Applied Optics, 23: 134-138, 1984.

[2] Corp, L.A., McMurtrey, J.E., Chappelle, E.W, Daughtry, C.S.T., Kim, M.S. "UV Band Fluorescence (in vivo) and its Applications to the Remote Assessment of $\mathrm{N}$ Fertilization Level", Remote Sens. of Environ., 61:110117, 1997.

[3] Cecchi, G., Bazzani, M., Raimond, V., and Pantani, L., "Fluorescence LIDAR in vegetation remote sensing: system features and multiplatform operation," Proc. Internat. Geoscience and Remote Sens. Symp. 1:637$639,1994$.

[4] Lichtenthaler, H. K., M. Lang, M. Sowinska, F. Heisel, and J. A. Miehe, "Detection of vegetation stress via a new high resolution fluorescence imaging system," Plant Physiol., 148:599-612, 1996.

[5] Chappelle, E., McMurtrey, J., and Kim, M., "Identification of the pigment responsible for the blue fluorescence band in the laser induced fluorescence (LIF) spectra of green plants, and the potential use of this band in remotely estimating rates of photosynthesis," Remole Sens. Environ., 36: 213-218, 1991.

[6] Cerovic, Z., M. Bergher, Y. Goulas, S. Tosti, and I. Moya, "Simultaneous measurement of changes in red and blue fluorescence in illuminated isolated chloroplasts and leaf pieces: The contribution of NADPH to the blue fluorescence signal," Photosynthesis Research, 36: 193-204, 1993. 
